\title{
Estratégia geopolítica e hegemonia de classe: para uma análise materialista-histórica de política externa'
}

\author{
Geopolitical strategy and class hegemony: towards a \\ historical materialist foreign policy analysis
}

\author{
Bastiaan van Apeldoorn ${ }^{a}$
}

\author{
Tradução de Caio Bugiato ${ }^{b}$
}

Resumo Este artigo procura estabelecer os fundamentos para uma análise materialistahistórica de política externa. Embora exista uma vasta literatura marxista sobre, especialmente, o imperialismo estadunidense, é pequeno o número de pesquisas empíricas sistematizadas sobre formulação de política externa nessa perspectiva. A maioria das contribuições nessa tradição, incluindo as mais recentes do debate sobre o “novo imperialismo", são geralmente exercícios abstratos em grande teoria - importantes e perspicazes, mas não necessariamente direcionados à pesquisa empírica. De outro lado, os estudos mais empíricos que existem sobre formulação de política externa (estadunidense) geralmente tendem a sofrer com a falta de teorização adequada. Procurando suprir essa lacuna este artigo primeiramente examina de forma crítica a atual (e crescente) literatura materialista-histórica sobre a geopolítica (e suas ligações com o capitalismo global) e então busca ir além, oferecendo uma estrutura $[\mathrm{F}]^{2}$ analítica que pode ser aplicada em pesquisa empírica. Um ponto de partida teórico é o que Harvey identifica como as lógicas territorial e capitalista de poder, dialética e intrinsicamente

1 Nota do Tradutor: Artigo publicado originalmente sob o título "Geopolitical strategy and class hegemony: towards a historical materialist foreign policy analysis”, na revista Spectrum Journal of Global Studies, vol. 6, n.1. O texto original pode ser encontrado no periódico citado, no endereço: http://spectrumjournal.net/geopolitical-strategy-and-class-hegemony-towards-a-historical-materialist-foreign-policy-analysis/. A tradução foi autorizada pelo comitê editorial da revista, particularmente pelo prof. Faruk Yalvaç, a quem agradecemos a diligência.

a Bastiaan van Apeldoorn é professor associado em Relações Internacionais no Departamento de Ciência Política e Administração Pública da Vrije Universiteit, Amsterdã. Ele é membro-fundador do Elite Power Investigations Centre (EPIC) e chair do Centro de Pesquisa para Economia Política Internacional de Amsterdã (ARCIPE). Sua pesquisa se concentra no papel da classe e do poder das elites na economia política global e europeia e na geopolítica contemporânea.

b Professor adjunto A-1 do Departamento de História e Relações Internacionais da Universidade Federal Rural do Rio de Janeiro.

2 N. do T. O autor utiliza o termo estrutura em dois sentidos: o primeiro, structure em inglês, indica um sistema de relações recíprocas entre elementos que se condicionam mutuamente, isto é, é um conceito que identifica um sistema social; o outro, framework em inglês, indica um conjunto de ideias sistematizas para o propósito de análise científica. Ao longo do texto traduzido o segundo sentido, framework, é indicado com a letra F entre colchetes após a palavra estrutura. 
relacionadas. Mas considerando que muitos acadêmicos materialista-históricos concordariam com essa noção abstrata, a questão é não apenas por que mas também como (na prática) elas estão relacionadas e como podemos estudar os efeitos dessa relação intrínseca. Para tal, argumentamos que é preciso ir além de postular lógica(s) abstrata(s) e analisar a agência concreta das forças sociais que constituem o elo entre Estado e capital. Argumentamos que a classe é a força crucial de mediação e o elo perdido da literatura. Enfocar a classe e a estratégia de classe nos proporciona uma base para análise empírica e sistemática de processos concretos mediante os quais estratégias geopolíticas dos Estados capitalistas (a maioria) são formuladas e implementadas.

Palavras-chave Relações Internacionais Materialista-históricas; Geopolítica e Estrutura Social; Geopolítica Capitalista; Classe e Geopolítica; Segurança da Classe Dominante.

Abstract This article seeks to lay the groundwork for a historical materialist foreign policy analysis. Although there is a huge Marxist literature on especially US imperialism, there is little in the way of systematic empirical research on foreign policy-making from this perspective. Most contributions in this tradition, including more recent ones in the debate on the "new imperialism" are often rather abstract exercises in grand theory - important and insightful but not necessarily directly amenable to empirical research. On the other hand, the radical empirical studies of (US) foreign policy-making that we do have often tend to suffer from a lack of adequate theorization. Seeking to bridge this gap this article first critically reviews the current (and expanding) historical materialist literature on geopolitics (and its link to global capitalism) and then seeks to move beyond that by offering an analytical framework that can be applied to actual empirical research. A theoretical point of departure is that what Harvey identifies as the territorial and capitalist logics of powers are dialectically and hence internally related. But whereas many historical materialists would agree on this abstract notion, the question, however, is not only why but also how (in practice) they are thus related, and how we can thus study the effects of this internal relation. For this, I argue, we need to go beyond positing any abstract logic(s), and analyse the concrete agency of social forces constituting the link between state and capital. I argue that class is the crucial mediating force here and the missing link in much of the literature. A focus on class and class strategy provides us with a basis for a systematic empirical analysis of the concrete processes through which geopolitical strategies of (major) capitalist states are formulated and implemented.

Keywords Historical Materialist IR; Geopolitics and Social Structure; Capitalist Geopolitics; Class and Geopolitics; Ruling Class Security. 
É possível afirmar que as análises de política externa - há muito reconhecido como um importante subcampo das Relações Internacionais (RI) - passam por certo ressurgimento - por exemplo, com o lançamento da nova revista Foreign Policy Analysis em 2005 e a publicação de vários novos livros introdutórios, além de uma antologia de cinco volumes3 ${ }^{3}$. Enquanto a análise de política externa nas RI tem se orgulhado de trabalhar com "teorias de médio alcance", tem sido sugerido que esse interesse precisa estar articulado com "grandes teorias" mais tradicionais ${ }^{4}$ sobre o sistema político internacional como um todo, aproximando então a análise de política externa do núcleo da disciplina Relações Internacionais (Smith; Hadfield; DunNe, 2008; Hudson, 2007). Nesta, embora o "Marxismo" seja - pelo menos na Europa - reconhecido como uma das principais teorias ou abordagens "alternativas", discussões sobe o Marxismo ou perspectivas teóricas materialista-históricas estão notavelmente ausentes dos debates acerca de teoria de política externa. Na antologia supracitada em mais de 1600 páginas nem uma única contribuição foi inclusa que pudesse ser razoavelmente identificada como materialista-histórica ${ }^{5}$. É possível afirmar que essa ausência é menos resultado de uma tentativa consciente de marginalizar o Marxismo pelo mainstream não marxista e mais uma compreensão do fato que muito poucos acadêmicos materialista-históricos nas RI fazem "análise de política externa", mesmo que amplamente definida, preferindo identificar-se com o subcampo Economia Política Internacional (EPI) e fazer pesquisa sobre estruturas e processos mais abrangentes do capitalismo global - mas sem conexão com os processos concretos de formulação de política externa. Apesar de existir uma impressionante - e recentemente revigorada - literatura (neo)marxista sobre imperialismo (especialmente o estadunidense), grande parte dela é geralmente de natureza mais teórica e as referências empíricas servem de ilustração para argumentos mais abstratos. Essa relativa negligência em relação à política externa persistiu apesar da recente "virada geopolítica", na qual acadêmicos materialista-históricos em RI se propuseram ao debate e à análise de relações (intrínsecas) entre o capitalismo global,

3 Carlsnaes e Guzzini (2011).

4 N. do T. Teorias de alcance médio (middle range theories) são teorias que examinam fenômenos específicos e mais restritos, enquanto grandes teorias (grand theories) são teorias gerais que se propõe explicar fenômenos gerais e suas variedades em diferentes tempo e espaço.

5 Da mesma forma, em um livro conhecido e recente sobre análise de política externa (Sмiтн; Hadfield; Dunne, 2008; Hudson, 2007) encontramos capítulos sobre os habituais Realismo, Liberalismo e Construtivismo, mas nenhum capítulo sobre o Marxismo. Em contraste, na maioria das vezes, pelo menos em livros europeus (Reino Unido), o marxismo, às vezes rotulado de estruturalismo ou radicalismo, está entre as principais perspectivas teóricas incluídas na discussão da Teoria de Relações Internacionais. 
de um lado, e a geopolítica, do outro ${ }^{6}$. Apenas recentemente alguns acadêmicos materialista-históricos começaram a produzir análises empíricas e sistematizadas sobre processos concretos de formulação de política externa e seus determinantes sociais e políticos7.

$\mathrm{Na}$ realidade a maior parte da literatura materialista-histórica que toca nas questões de política externa tende a enfatizar estruturas (históricas e duradouras), enquanto pouca atenção é dada ao papel da agência (em fazer as estruturas durarem ou modificá-las). Há assim necessidade de desenvolver uma estrutura [F] que conecte explicações histórico-estruturais às análises da prática concreta em política externa ${ }^{8}$. Este artigo procura contribuir para o desenvolvimento de tal estrutura [F] e de modo geral demonstrar a relevância da perspectiva materialista-histórica para entender a (formulação de) política externa dos Estados capitalistas avançados na economia política global contemporânea. Tentamos mostrar como uma perspectiva materialista-histórica é necessária para revelar as fontes sociais da política externa, que do contrário permanecem fora de vista. $\mathrm{O}$ artigo daqui em diante está organizado da seguinte forma: na primeira parte procuramos desenvolver e oferecer uma crítica às recentes contribuições materialista-históricas sobre a teorização da relação geopolítica e capitalismo global. Partindo da análise sobre as estruturas das relações geopolíticas para a análise da formulação geopolítica, ou seja, política externa, estratégias, na segunda parte procuramos delinear uma estrutura [F] analítica para uma análise materialista-histórica de política externa em que a classe (agência) é o nexo crucial.

\section{GEOPOLÍTICA E ESTRUTURA SOCIAL: FUNDAMENTANDO A ANÁLISE DE POLÍTICA EXTERNA NO MATERIALISMO HISTÓRICO PARA RI.}

Tradicionalmente na disciplina Relações Internacionais o que é identificado como o subcampo Análise de Política Externa (APE) se distingue das chamadas teorias sistêmicas das relações internacionais - particularmente o Neorrealismo, que considera os Estados como entidades autônomas e autossuficientes abstraídos

6 Sobre isso, verificar Teschke (2003); Teschke e Lacher (2007); Anievas (2010); Callinicos e Rosenberg, (2007b); Lacher, (2005); Callinicos (2009); Callinicos (2007); Van der Pijl (2006); Rupert e Smith (2002).

7 Halperin (2009); Anievas (2011) e várias contribuições na Special Section.

8 Este não é o primeiro artigo a apontar a necessidade disso. Pozo-Martin (2007, p. 552) também defendeu um conceito marxista de geopolítica que prestasse devida atenção à "agência e microfundações". No entanto, isso continua sendo uma exceção e essa defesa até agora não produziu poucas consequências. Embora este artigo não pretenda oferecer uma teoria desenvolvida de tais microfundações, ele pretende desenvolver mais adiante uma análise materialista-histórica da política externa nesse sentido. 
da sociedade (WALTZ, 1979) - ao defender que a caixa-preta do Estado precisa ser aberta. Igualmente, o que é considerado nas RI como variáveis de nível da unidade (ou seja, o que está no interior do Estado), analistas de política externa chamam de "ator-orientado" (Hudson, 2005). Na realidade, para desenvolver uma abordagem materialista-histórica de análise de política externa devemos reconhecer a importância da agência como um meio através do qual relações geopolíticas são reproduzidas e transformadas. Mas ao passo que a APE convencional, alinhada com a ciência política pluralista, concentra-se em líderes de governos, burocratas e (mais raramente) "grupos de interesse" (Breuning, 2007; Hudson, 2007) em competição como atores separados de estruturas sociais mais profundas, uma abordagem materialista-histórica da política externa defende que precisamos conectar a agência da política externa com estruturas de relações sociais capitalistas e forças sociais geradas por esta.

\section{GEOPOLÍTICA E CAPITALISMO GLOBAL: UMA PROBLEMÁTICA MATERIALISTA- HISTÓRICA}

Um entendimento estrutural da geopolítica a partir da tradição marxista nos leva a uma problemática chave acerca das relações entre, de um lado, capitalismo como sistema global, transnacional e com relações e práticas parcialmente desterritorializadas e, do outro lado, um sistema de Estados modernos em que a política é organizada em forma de entidades soberanas envolvidas em relações horizontais (não hierárquicas). Uma premissa chave de qualquer abordagem materialista-histórica deve ser que as relações e práticas que constituem a "geopolítica" contemporânea estão intrinsecamente conectadas com as relações e práticas que constituem o capitalismo (global)9. De fato, além do conceito de capitalismo (e sua especificidade histórica), o que distingue o materialismo histórico de outras perspectivas é a busca por desvendar as íntimas relações entre, de um lado, o prevalecente regime de extração de mais-valia, definido pelas relações sociais de produção, e, de outro lado, diferentes sistemas de dominação (diferentes formas de Estado), incluindo as relações e práticas entre eles ${ }^{10}$.

A mais ampla e ambiciosa teoria materialista-histórica nesse sentido é o projeto de Kees van der Pijl (2007) sobre "modos de relações exteriores", em que "aspectos das relações sociais em si" devem ser vistos em conexão com "modos de produção", nos quais relações de classe emanam das forças de produção (VAN DeR PIJL, 2007,

9 Rosenberg (1994); Rupert (1993); Wood (2003); Van der Pijl (2007).

10 Um trabalho seminal a este respeito, analisando diferentes sistemas de dominação na transição do feudalismo para o absolutismo é de Perry Anderson (1974). 
p. 19). Embora os méritos intelectuais desse projeto muito original em expandir a área de RI sejam muitos, o escopo da teoria é muito amplo para o propósito mais limitado deste texto. Ao analisar o conjunto de "determinações complexas" que formam as relações exteriores, as íntimas conexões apresentadas entre elas e os modos de produção permanecem num nível muito alto de abstração para este texto, preocupado menos com (variações de) relações exteriores ao longo da história e mais com estratégias geopolíticas concretas, inseridas em um "modo de produção" particular, ou seja, o capitalismo.

Uma das tentativas mais sistemáticas de teorizar sobre a relação entre geopolítica e estruturas sociais é a "teoria de relações sociais de propriedade" de Brenno Teschke (2003, p. 7), que propõe que ordens geopolíticas são "governadas pelo caráter de suas unidades constitutivas, as quais por sua vez estão assentadas em relações específicas de propriedade prevalecentes no seu interior" (TEsChKE, 2003, p. 46). Teschke dá atenção ao papel da agência, a qual ele vê entrelaçada dialeticamente com a estrutura (TESCHKE, 2003, p.56), porém ele apresenta uma explicação histórico-estrutural na qual a estratégia geopolítica é derivada das dadas estruturas de relações sociais de propriedade (de classe). Desse modo, Teschke escreve que "relações de propriedade definem as estratégias da classe dominante, que explicam a conduta internacional" (TEschke, 2003, p. 218), então estratégias de classe traduzem estruturas sociais (de propriedade) em comportamento internacional (Teschke, 2003, p. 220). Devido a essa discutível abordagem unilateral sobre a dialética entre estrutura e agência, a teoria das relações sociais de propriedade pode precisamente descrever diferenças entre sistemas (feudal, absolutista e capitalista), mas não pode adequadamente explicar variações dentro dos sistemas, sincrônica ou diacronicamente. Por isso precisamos trazer a agência de modo mais completo em nossas explanações. Mas primeiro devemos entender mais profundamente as estruturas que constituem a ordem geopolítica capitalista contemporânea revendo algumas recentes intervenções no revigorado debate (materialista-histórico) sobre o imperialismo.

\section{GEOPOLÍTICA CAPITALISTA: TEORIZANDO AS ESTRUTURAS DO IMPERIALISMO MODERNO}

Como o Marxismo político corretamente enfatiza, o que distingue o capitalismo do feudalismo é que enquanto neste "o político" e "o econômico" estão fundidos e personalizados nas normas do senhor ou do rei, aquele é caracterizado por uma separação ideológica e institucional de ambos (ANDERson, 1974; WoOD, 1995; WoOD, 2003; TeschKe, 2003). As implicações estruturais disso não 
são, contudo, imediatamente claras e estão sujeitas a controvérsias nos recentes debates materialista-históricos sobre geopolítica. A questão diante de nós, então, é como teorizar a natureza da geopolítica capitalista em termos de relação entre duas esferas que são separadas no capitalismo, ainda mais de uma perspectiva materialista-histórica que as enxerga intrinsecamente relacionadas mediante os efeitos estruturantes das relações sociais capitalistas.

Com a finalidade de fazer um resumo desse debate e da nossa própria posição nele, comecemos com a visão recente segundo a qual a relação entre capitalismo e geopolítica é um não problema, uma vez que esta não é vista como uma esfera separada e relevante quando consideramos o sistema interestatal como um todo. A conhecida tese de William Robinson (2004) é que, com o surgimento de uma classe capitalista transnacional (CCT) globalmente integrada, testemunhamos a emergência de um Estado global transnacional que transcende a noção de interesses "nacionais" distintos, dado que os Estados nacionais, "capturados por forças capitalistas transnacionais", estão "sendo transformados e cada vez mais funcionalmente absorvidos por uma ampla estrutura institucional transnacional" (RobINSON, 2007, p. 17). Em outras palavras o capital global domina e domina por meio de um Estado global, por isso não há razão para estudar estratégias geopolíticas nacionais diferentes da expressada periodicamente pela dominação de classe global (que não são mais estratégias nacionais - ou geopolíticas - pois todos funcionam para servir os mesmos interesses capitalistas transnacionais). Temos um mundo, então, em que o poder territorial foi dissolvido por inteiro e a geopolítica se tornou relíquia do passado.

Wood (2003) e Callinicos (2007) defendem, ainda que com motivos diferentes, que o mundo do capitalismo global é e provavelmente continuará sendo dividido em unidades territoriais soberanas ${ }^{11}$. Segundo Wood, a "forma política da globalização" é e continuará sendo a pluralidade de Estados nacionais, uma vez que "nenhuma forma concebível de 'governança global' poderá desempenhar os tipos de funções coercitivas diárias que os Estados desempenham e o capital precisa" (WoOD, 2003, p. 20). A isso se pode adicionar o argumento que para o capital global o Estado mundial, um "império mundial" como Wallerstein (1974) o chama, é perigoso: solaparia os potenciais benefícios do capital, dado que este perderia a maior parte

11 Na verdade, Robinson não nega que o mundo é dividido em Estados-nação e que esses Estados tendem a persistir - ele apenas argumenta que eles estão se tornando nós institucionais de uma incipiente estrutura do Estado global; Robinson, op.cit. nas notas 20 e 21. Nesse caso, no entanto, a persistência de um sistema interestatal não possui o significado analítico sugerido aqui. Para uma crítica penetrante sobre Robinson, ver Anievas (2008); Davidson ( 2010); Teschke e Lacher (2007); Lacher (2005). 
do seu poder estrutural, isto é, a habilidade de se mover pelas fronteiras nacionais ou fugir de regimes nacionais não acomodatícios o suficiente.

Outra questão é até que ponto a persistência da territorialidade também tende a levar diferentes Estados capitalistas à rivalidade. Aqui as posições claramente divergem. Para Wood, em um sistema dominado por Estados capitalistas, no qual "todas as relações internacionais são intrínsecas ao capitalismo e governadas por imperativos capitalistas" (Wood, 2003, p. 127), a geopolítica não envolve mais "acumulação geopolítica" - isto é, o engrandecimento de territórios característico de sistemas pré-capitalistas (TESCHKE, 2003) - precisamente porque o capitalismo é um sistema de dominação que é baseado na separação entre "o econômico" e "o político". Wood escreve que, por causa da capacidade única do capitalismo "de separar o poder econômico do poder extraeconômico", "o imperialismo capitalista pode exercer sua dominação por meios econômicos" e foi capaz de estender "o alcance da dominação imperial muito além da capacidade da dominação política direta ou da ocupação colonial" (Wood, 2003, p. 5, 12, 21; Wood, 2006, p. 9-23). Da mesma forma, Teschke sustenta que o advento da acumulação geopolítica capitalista - após as revoluções europeias dos séculos XVIII e XIX - foi substituído por uma "lógica não territorial de apropriação de mais-valia internacional baseada em contratos não políticos entre cidadãos privados” (TЕSChKE, 2003, p. 263), ou seja, a rivalidade interestatal na anarquia internacional foi substituída pela rivalidade entre empresas no livre mercado.

No entanto, mesmo enfatizando a lógica não territorial do poder capitalista, Wood também afirma que "o poder econômico não pode existir sem força extraeconômica" e que "o Estado é mais essencial que nunca para o capital” (Wood, 2003, p. 5), não apenas para subordinar trabalhadores, mas do mesmo modo para abrir e manter abertas as economias à exploração imperialista (Wood, 2003, p. 20-24). Apesar da expansão territorial se tornar obsoleta (e geralmente disfuncional), o poder coercitivo dos Estados territoriais - sobretudo dos EUA de sustentar seu "império do capital" - permanece crucial. Mas como o imperialismo estadunidense é o único relevante, a competição geopolítica é fortemente atenuada ${ }^{12}$.

Em contraste, Callinicos enxerga a rivalidade geopolítica como sendo endêmica ao capitalismo. Ele disserta sobre o imperialismo capitalista, ou imperialismos, pois para ele este é por definição um fenômeno plural, como a intersecção da competição econômica (entre capitais nacionais) com a competição geopolítica (entre Estados nacionais) (2009, p. 72). Embora Callinicos possa ver os dois como

12 Para uma crítica, Callinicos (2009), p. 75-81. 
intrinsecamente relacionados, em sua teoria a conexão entre essas duas formas de competição, isto é, como e por que elas se tornam articuladas na prática, não é clara. Em vez disso, somos mais uma vez lembrados da relativa autonomia da competição geopolítica, o que o próprio Callinicos (2007, p. 542) chama de o necessário "momento realista na análise marxista das relações internacionais".

\section{A PERSISTÊNCIA DA GEOPOLÍTICA NA ERA DA TRANSNACIONALIZAÇÃO}

$O$ argumento de Wood segundo o qual o imperialismo capitalista não depende de expansão territorial faz sentido teoricamente e parece corroborado empiricamente pela história do capitalismo, especialmente pelo imperialismo estadunidense desde 1945 (Apeldoorn; De GrAafF, 2012, p. 539-608). Então, embora estejamos além da acumulação geopolítica, não estamos além do poder territorial do Estado, que em parte facilita e sustenta a acumulação capitalista. A questão é se estamos também além dos conflitos geopolíticos interestatais.

O fato é que atualmente o mundo é ainda dividido em Estados nacionais soberanos e alguns deles comandam recursos financeiros, políticos e militares que os permitem aplicar o poder do Estado externamente, de maneira que por vezes tendem a colidir com outros Estados que fazem o mesmo. $\mathrm{O}$ quanto isso vai acontecer depende da interação dialética entre estrutura e agência. Do lado estrutural, é possível argumentar que essas formas de rivalidade geopolítica são menos propensas a acontecer não apenas por causa da transnacionalização da produção e das finanças capitalistas, mas também porque essa transnacionalização gera um processo de formação transnacional de classe, integrando organicamente complexos Estado-sociedade nacionais, criando um espaço transnacional livre para o capital (VAN DER PIJL, 1998). Nesse espaço, é possível dizer que a competição entre Estados tende a ser restrita à competição por IDE/Investimento Externo Direto (em vez de promover o próprio capital nacional) e tal "corrida competitiva" não tende a se espalhar para a esfera da segurança, pois prejudicaria os interesses do capital integrado globalmente. Embora isso descreva certamente um importante aspecto da ordem mundial capitalista neoliberal das últimas décadas, não é tudo.

Como mencionado por Robinson, a formação de uma CCT não está completa nem é necessariamente irreversível, nem fez desaparecer completamente interesses e identidades nacionais (de classe). De fato a classe continua a ser constituída como um ator social também dentro de diferentes contextos nacionais - nos quais a agência de classe é orientada para o nacional a para políticas nacionais, inclusive política externa. Na realidade, enquanto Robinson (2007, p. 5-26; 2007b, p. 71-93) 
acusa autores como Wood, Callinicos e Harvey (ver adiante) de reificar o Estado nacional, Robinson tende a reificar a classe capitalista transnacional.

Embora o fenômeno da formação transnacional de classe, isto é, a formação de frações de classe com particular consciência de classe transnacional e perspectiva coletiva, tenha sido evidenciado ao menos em contextos histórica e geograficamente determinados, como no contexto atlântico pós-guerra (VAN DER PIJL, 1984) e no contexto europeu do processo de integração em que a formação de uma classe capitalista transnacional foi a mais forte, a evidência empírica não aponta para a formação de uma única CCT globalmente integrada, como Robinson alega (2004). De fato, uma pesquisa mostra que quanto maior a escala, menos volumosos se tornam esses processos transnacionais. Carroll (2010) mostra que no âmbito global não encontramos redes emergentes de classe transnacionais, mas elas estão sobrepostas em camadas nacionais permanentes, cujas redes ainda são, no geral, mais densas. Concomitantemente, o capital transnacional também continua envolvido em estruturas sociopolíticas nacionais específicas. Isso não é apenas ideológica e institucionalmente determinado, pois também o capital transnacional ainda tem em geral fortes bases e mercados nacionais (especialmente quando reside em Estados maiores). Classes nacionais, ligadas à orientação do capital transnacional, mas também parcialmente inseridas no capital nacional, persistem "por baixo" de processos incompletos e regionalmente configurados de formação transnacional de classe e essas diferentes classes nacionais, sob certas condições e dado o desenvolvimento desigual e combinado aludido anteriormente, podem ainda ter conflitos de interesses e perspectivas que podem se alastrar para competição geopolítica.

Claramente tal competição continuou ao longo do século XX e no século XXI entre o Ocidente liberal (e expansivo) e Estados contendores não liberais (pode-se dizer não completamente capitalistas) (VAN DER PIJL, 2006). Mas deixando isso lado - nossa preocupação aqui é com os Estados capitalistas avançados - mesmo no interior do Ocidente, como Van der Pijl argumenta (2006), velhas rivalidades históricas não foram completamente transcendidas no que ele chama de área central lockeana expandida ao longo dos séculos passados. De modo geral, processos de globalização e de transnacionalização não são necessariamente irreversíveis e supor que esses processos vão continuar até que o Leviatã capitalista global seja criado seria produzir uma teleologia. A atual crise europeia é um caso ilustrativo dessa questão. Além disso, o que causa as atuais forças centrífugas na Europa são, além do modelo defeituoso da União Monetária e Econômica, os grandes e crescentes desequilíbrios econômicos na Zona do Euro - um exemplo regional do modo geograficamente desigual através do qual o desenvolvimento capitalista se realizou. Mesmo se não 
recorrermos ao conceito trotskista do "desenvolvimento desigual e combinado" (CAllinicos, 2009, p. 88-93; Allison; Anievas, 2010, p. 197-214), ou como Harvey (2003) salienta que o capital se concentrou em complexos regionais, é evidente que essas diferenças espaciais do desenvolvimento capitalista ao menos potencialmente conduzem a uma dinâmica geopolítica de competição interestatal. Mas ao evitar a retificação "do transnacional", autores como Callinicos, que atesta a persistência da rivalidade interimperialista, tendem a reificar "o geopolítico". Embora Callinicos alegue não fazer, como fazem os realistas, uma abstração do "Estado em face das relações sociais e econômicas nas quais está inserido" (CALLINICOS, 2009, p. 83), isso é precisamente o que ele tende a fazer ao final. O que é ilustrado pela maneira como ele enxerga a atual ordem mundial, caracterizando-a como a continuação de uma duradoura competição entre "Grandes Potências capitalistas avançadas" divididas em "centros de poder competitivos (...) da Europa Ocidental, América do Norte e Leste Asiático" (CALLINICOS, 2009, p.17). O que é completamente subestimado é, por exemplo, a diferença de natureza e de trajetória histórica do desenvolvimento capitalista e das relações sociais subjacentes no "Leste Asiático" (como quer que se queira definir esta região) comparados com a Europa Ocidental. Há inclusive pouca evidência empírica para sustentar a noção de que EUA e União Europeia atualmente são rivais geopolíticos (CAFRUNY; RYNER, 2007).

\section{ALÉM DA “AUTONOMIA RELATIVA” DO GEOPOLÍTICO}

A raiz do problema nessa tendência de reificar o conflito geopolítico está, na nossa visão, na forma como Callinicos tenta estipular um grau de autonomia para o geopolítico (2009, p. 73), de modo que as conexões internas com as relações sociais capitalistas se perdem. Uma tendência similar pode ser encontrada na conhecida distinção (ARRIGHI, 1994, p. 33-34) de David Harvey entre a "lógica capitalista" e a "lógica territorial" de poder, em que o imperialismo capitalista representa uma "contraditória” fusão entre ambas (2003, p. 27). Harvey insiste que essas lógicas devem ser vistas "distintas uma da outra", frequentemente em conflito e também entrelaçadas contraditoriamente, isto é, dialeticamente (HARVEY, 2003, p. 29-30), porém ele não explica como esses poderes imperialistas dialéticos vão além e formam políticas externas imperialistas ${ }^{13}$. Ao final, essas lógicas aparentam estar relacionadas apenas externamente (RoBinson, 2007). Mas, como Brenner argumenta (2006, p. 80-81), a alegada autonomia da lógica territorial de poder

13 Esta crítica a Harvey não é para desviar a atenção dos grandes méritos de seu trabalho sobre a compreensão do moderno imperialismo capitalista, especialmente sua teoria da sobre acumulação e acumulação por despossessão como estratégia imperialista. 
carece de um raciocínio claro: enquanto os capitalistas de fato são forçados pela dinâmica da acumulação capitalista a continuar acumulando, não é claro por que os Estados seriam orientados pela "acumulação de controle territorial como um fim em si mesmo" (HaRveY, 2003, p. 81).

Concomitantemente, e alinhado à ênfase realista na autonomia do Estado, agentes do Estado tendem a serem vistos como uma classe separada ou ao menos como um grupo social autônomo com suas próprias "motivações e interesses", com a finalidade de "manter ou aumentar o poder de seu próprio Estado vis-à-vis outros Estados" (Harvey, 2003, p. 27; CAllinicos, 2009, p. 80-81). Novamente o problema dos mecanismos que motivariam os agentes de Estado não está especificado. Um possível candidato para explicar isso seria a lógica neorrealista da anarquia forçando os Estados a buscar poder a fim de sobreviver. Contudo, afora o fato de que os neorrealistas não concordam entre si se isso implica que os Estados têm o propósito de maximizar o poder (MEARSHEIMER, 2001), ou somente manter o que já têm (WALTZ, 1979), nem concordam em quais seriam os melhores meios para atingir esse alegado objetivo primordial, a história mostra variações nas estratégias de Estado, as quais não fica claro o quanto, ou mesmo se, essa lógica "sistêmica" pode explicar.

Obviamente, o materialismo histórico não nos ajudará a entender melhor a formulação de política externa se ele nos levar de volta ao primeiro passo, ou seja, a lógica realista da anarquia (Pozo-Martin, 2007, p. 551-563). Seguramente, o Estado não é simplesmente um agente do capital, mas postular que agentes do Estado formam um grupo separado com - por definição - seus próprios interesses é reduzir o papel do capital na conformação da política externa a um mero constrangimento estrutural: isto é, o Estado e seus agentes são motivados por sua própria lógica de procurar expandir o poder territorial, mas não são constrangidos pela lógica da acumulação de capital da qual são dependentes (CALlinicos, 2009, p. 85-86). Em Callinicos, essa mistura estrutural entre Marxismo e Realismo, agência de classe e ideologia de classe, apenas aparece como ideia adicional (CALLINICos, 2009, p. 93-100), com a ideologia de classe surgindo como variável adicional, para a qual a indeterminação da relação entre capitalismo e geopolítica cria um espaço de entrada, mas que permanece sem explicação.

A partir dessa literatura marxista recente sobre a natureza e a dinâmica da geopolítica, abordamos uma perspectiva - mais claramente representada por Teschke - que dá primazia completa para as relações de classes verticais e domésticas e enxerga relações geopolíticas horizontais como, sobretudo, expressão destas relações; e uma segunda perspectiva, na outra ponta - mais claramente representada por Callinicos - em que o capitalismo e a geopolítica não são tanto intrinsecamente 
relacionados, mas sim meramente cruzados, produzindo uma dinâmica complexa e "indeterminada" (CALlinicos, 2009, p. 15), que, todavia, é supostamente caracterizada pela persistente rivalidade entre grandes potências. Com a finalidade de desvendar a conexão intrínseca entre as relações sociais capitalistas e a geopolítica, em vez de substituí-la por uma definição ruim de "intersecção", argumentamos adiante que precisamos ir da análise sobre estruturas (econômicas) capitalistas para a agência de classe capitalista, sendo a classe o nexo entre Estado e sociedade, entre o político e o econômico e entre o capitalismo global e a geopolítica.

\section{ESTRATÉGIAS GEOPOLÍTICAS E 0 NEXO DA CLASSE}

O tipo de abordagem materialista-histórica da política externa que este trabalho procura desenvolver vai além dessas concepções materialistas-históricas que tendem a, como o Realismo, abstrair o Estado da sociedade e conceber o capital como mero constrangimento externo para os agentes do Estado que de outro modo operam independentemente. A independência destes em termos de "seus próprios interesses" (ANIEvAs, 2010, p. 609) não pode ser tomada como um dado a priori, nem podemos a priori assumir que sua dependência estrutural em relação ao capital tenderá a assegurar que os interesses característicos do capital serão atendidos. Em vez disso, ao postular teoricamente os interesses dos agentes do Estado, e baseado nisso derivar expectativas sobre o que eles tendem a fazer (por exemplo, maximizar o poder do Estado), argumentamos que é preciso acessar empiricamente o que eles fazem e subsequentemente explicar a agência dos agentes de Estado analisando o contexto social em que operam ${ }^{14}$. Como Teschke e Lacher escrevem: "a questão nunca é o que os agentes do Estado ou os capitalistas deveriam fazer ou deveriam ter feito de acordo com alguma lógica de tipo ideal, mas o que realmente fazem" (2007, p. 570).

De uma perspectiva materialista-histórica isso significa conectar a ação dos agentes do Estado com estruturas sociais mais amplas e com forças sociais, às quais o Estado e o poder do Estado estão intrinsecamente relacionados. De forma mais concreta, precisamos examinar empiricamente como agentes de Estado estão inseridos em um campo mais amplo de forças e como estão particularmente relacionados com a estrutura de classe geral, por meio da qual a conexão entre Estado e capital, além de mera "interdependência estrutural" (ANIEvAS, 2011; BLOCK, 1987), deve ser vista como intrinsecamente relacionada, através do processo de

14 Isso significa que devemos rejeitar igualmente qualquer conceito a priori de uma identidade de interesses entre agentes de Estado e capitalistas. Na verdade, uma possível divergência de seus interesses certamente não pode ser excluída de antemão (ANIEvAs, 2008, p. 199). 
formação (capitalista) de classe. Embora não se possa excluir que os agentes de Estado tenham interesses separados, eles teoricamente não devem ser vistos como apartados dos interesses (capitalistas) de classe. Em Estados capitalistas avançados, agentes não formam uma classe social separada, isto é, um grupo de pessoas que compartilha relações comuns com os meios de produção e que estruturalmente tendem a desenvolver práticas coletivas. É possível dizer que agentes do Estado podem formar uma "classe estatal" separada da sociedade (tal como possivelmente no "capitalismo de Estado" na China), onde a formação social não é (completamente) capitalista e a "dominação econômica" é ainda muito subordinada ao controle político exercido pelos agentes de Estado (sobre isso veja Van der Pijl a seguir). No capitalismo liberal (ocidental) ou o que Van de Pijl (2006, p. 16) chamou de "capitalismo integral", o capital é completamente emancipado da tutela do Estado e na sociedade forma efetivamente a verdadeira soberania. Nessas sociedades, é a classe capitalista - amplamente definida por aqueles que possuem e/ou controlam recursos produtivos e retiram a maior parte da sua renda assim como seu status social dessa relação de propriedade - que deve ser considerada a classe dominante. Isso significa que devemos analisar a posição e a ação dos agentes do Estado, por exemplo, na formulação e na execução de uma estratégia geopolítica do Estado, em relação a sua classe dominante e às práticas pelas quais ela procura efetivar e reproduzir sua dominação.

A classe é então vista como o nexo causal entre o processo de acumulação do capital e interesses concomitantes, de um lado, e interesses geopolíticos e estratégias de Estado, do outro ${ }^{15}$. Aqui precisamos ir além do clássico e confuso debate entre instrumentalismo e estruturalismo (Jessop, 2008; AnIEvas, 2011). Definitivamente, o argumento estruturalista está correto ao afirmar que o Estado é mais do que um instrumento nas mãos da classe dominante e ao indicar o poder estrutural do capital, em particular a dependência do Estado em relação à acumulação capitalista bem-sucedida. No entanto, os argumentos estruturalistas (nos quais Callinicos baseia-se implicitamente, por exemplo) sobre a dominação da classe capitalista falham na medida em que dispensam a agência e tendem a assumir que a dominação da classe capitalista se reproduz sem a necessidade de empenhar seu esforço para isso. Na realidade, a história prova sucessivamente que a classe capitalista (pró)ativamente procura reproduzir sua dominação ao propagar suas ideias e assegurar que estas estejam articuladas com o domínio do Estado. Que haja uma necessidade disso e que a mera dependência do poder estrutural do capital

15 Uma afirmação similar é feita por Van Der Pijl (2007), p. 13. 
não seja suficiente é de fato explicável sob uma visão relacional de classe, marxiana. Esta, diferentemente da teoria das elites, enfatiza o antagonismo social potencial e a dialética concomitante inerente à estrutura de classe capitalista e, portanto, a necessidade que a classe capitalista tem de gastar tempo, energia e dinheiro para defender e promover seus interesses, procurando de fato articulá-los com o interesse geral, vis-à-vis classes subordinadas que (potencialmente) resistem a essa dominação e potencialmente fazem pressão por interesses opostos. É por isso que precisamos integrar tanto a estrutura quanto a agência na nossa explicação sobre a dominação da classe capitalista - e os conflitos de classe subjacentes e lutas políticas e ideológicas por meio das quais essa dominação é reproduzida - como a chave para entender a formulação de política externa em Estados capitalistas avançados. Como indicado, classes podem ser, em alguma medida, transnacionais (e transnacionalizadas) e, portanto, devemos fazer análise de políticas externas nacionais com o elemento transnacional. Mas, como argumentamos, dada a incompletude da transnacionalização e a desigualdade geográfica do capitalismo transnacional, essas políticas de caráter nacional ainda devem ser mais do que apenas nodos de um mesmo Estado global (RoBinson, 2004). Continua a haver, assim, a necessidade de uma análise materialista-histórica de política externa nacional.

Esbocemos finalmente como podemos explicar resultados reais em termos de uma estratégia geopolítica conduzida por um determinado Estado capitalista. Deixemos a preocupação convencional da APE com o processo decisório (HuDSON, 2005) individual ou grupal em política externa, isto é, a explicação de por que indivíduos ou grupos $x$ tomam determinada decisão $y$ (Allison, 1971), para ir a uma abordagem materialista-histórica, que, sobretudo, dá sentido à estratégia, isto é, ao que na literatura (realista) é chamado de grande estratégia, correspondendo a uma visão abrangente dos "interesses" cruciais do "Estado" e de como melhor promovê-los e ao papel e à posição do Estado no mundo (LAYNE, 2006). Um primeiro ponto de partida é analisar a sustentação social e ideológica dessa estratégia e o propósito social particular a que serve. No próximo passo, procuramos explicar essa sustentação além da análise construtivista de ideias, ao colocar os agentes do Estado responsáveis pela estratégia geopolítica em seu contexto social, isto é, o contexto no qual a estratégia é produzida.

\section{COLOCANDO OS AGENTES DE ESTADO EM SEU CONTEXTO SOCIAL: UMA ESTRUTURA [F] ANALÍTICA}

Para evitar qualquer reificação do Estado, precisamos reconhecer que "a atividade do Estado é sempre a atividade de indivíduos particulares que atuam dentro 
de um contexto social particular" (WIGHT, 2004, p. 279). Assim, se a formulação de política externa é o nosso explanandum, faz sentido começar com os atores (formalmente) responsáveis pela formulação dessa política e, em seguida, descobrir como sua agência é possibilitada e condicionada por certas estruturas.

Propomos distinguir analiticamente pelo menos duas dimensões estruturais. A primeira se refere ao contexto social, ou posição social, dos atores envolvidos. Podemos associar a posição social a um determinado papel, como professor universitário ou ministro de relações exteriores - com poderes, direitos, deveres e expectativas normativas associadas a esse papel. Mas para obter um entendimento mais profundo, precisamos conceituar isso de forma mais ampla como o conjunto de estruturas sociais que definem a situação em que um ator se encontra e que são intrínsecas a sua atuação específica (BHASKAR, 1979, p. 153; ARCHER, 1995). A posição social pode fazer o ator ser visto como ele é, constituindo sua identidade particular, gerando um conjunto de interesses e ideias ou visão do mundo e moldando suas práticas de acordo com aquelas. Além disso, estar posicionado de forma particular significa ocupar uma posição particular dentro das relações de poder social (geralmente diferentes, mas sobrepostas) - definindo em que medida se é capaz de exercer poder sobre outros, mas também em que medida se está sujeito à coerção ou à influência de outros atores. Definido assim, embora não necessariamente imutável, a posição social é geralmente algo mais duradouro.

A posição social mais básica a partir de uma perspectiva materialista histórica é, claro, a classe, e, portanto, como as pessoas se relacionam com a mais fundamental estrutura da sociedade - mais fundamental porque, mais do que qualquer outra coisa, essa estrutura no capitalismo molda "a distribuição das condições estruturais de ação" (BASHKAR, 1979, p. 54) Assim, um capitalista tem uma posição social particular gerada por sua posição dentro das relações de produção prevalecentes, e, em virtude de ocupar essa posição, engaja-se em certas práticas (como a exploração do trabalho assalariado) e também pode ter ideias ou crenças particulares. As ideias aqui não podem ser reduzidas à posição social que ocupa um agente, mas tampouco podem ser entendidas como existentes independentemente dessa posição, isto é, da estrutura social em que qualquer prática ideacional está inserida.

A próxima dimensão estrutural que podemos distinguir analiticamente é mais contingente e mais externa ao ator, assim como mais ligada ao papel particular que um ator está desempenhando. Nós aqui nos referimos especificamente ao contexto ou ambiente externo para o qual a conduta estratégica de alguém está orientada. Assim, por exemplo, para um capitalista, o contexto pode ser um determinado mercado em que ele compete (a natureza e grau de competição que enfrenta e, 
portanto, o poder de mercado que ele possui). Se essas condições de mercado mudam, sua posição social como um capitalista não necessariamente muda, porém, em um caso limite, o mercado pode expulsá-lo dos negócios, fazendo com que, em última instância, ele deixe de ser um capitalista. Deve-se notar também que isso é, de fato, uma distinção analítica e que, na realidade, os limites entre as dimensões podem ser turvos. Por exemplo, entre diferentes tipos de capitalistas, podemos argumentar que um capitalista monopolista tem um conjunto diferente de interesses e perspectivas do que um que opera em mercados totalmente competitivos. Além disso, se o ambiente externo muda, pode afetar a sua posição social, bem como suas ideias. No entanto, sustentamos que esses efeitos interativos podem ser utilmente distinguidos da posição social inicial que alguém teve antes de enfrentar um determinando ambiente particular (em mudança). Vejamos agora como essa conceitualização poderia ser aplicada em uma análise materialista-histórica de política externa.

No que diz respeito à posição social, é evidente que se deve notar que, emanado do Estado, o papel dos funcionários do Estado responsáveis pela formulação de uma estratégia geopolítica abrangente é definir e propagar os interesses cruciais do Estado $^{16}$. Esta obviedade, no entanto, não diz nada sobre o que esses interesses são. Em vez de assumir, como na chamada teoria neorrealista de Relações Internacionais, que o interesse nacional pode ser derivado da necessidade objetiva de um Estado pela sobrevivência em um sistema anárquico, o ponto de partida aqui é que os interesses nacionais são construções políticas que atendem a um propósito social particular. Isso significa então analisar como tomadores de decisão estão operando em um amplo campo de forças sociais. Essas forças podem adotar estratégias específicas para o Estado com a finalidade de moldar a aplicação do poder estatal, ou seja, políticas de Estado específicas. Dentro seu papel particular, tomadores de decisão podem estar mais ou menos sujeitos a tais influências.

Aqui, então, precisamos teorizar não só sobre a natureza do Estado capitalista em geral e os constrangimentos estruturais decorrentes que agem sobre os agentes estatais, mas analisar empiricamente a forma específica do Estado no caso em questão. Por exemplo, o conceito de Jessop de seletividade estratégica do Estado é útil na medida em que se refere ao fato de que os Estados podem ser mais

16 Além disso, a chamada abordagem da política burocrática na APE (baseada no clássico de Allison de 1971) enfatiza que funcionários que ocupam diferentes cargos dentro do executivo tendem a assumir diferentes papéis e interesses divergentes. Além do fato de que empiricamente essa abordagem produziu, na melhor das hipóteses, resultados ambíguos, faz pouco sentido considerar estratégia geopolítica (ao invés de decisões individuais) como resultado da política burocrática. 
abertos para algumas forças sociais do que outras e assim selecionar ou favorecer certas estratégias e interesses sobre outros. Dada uma seletividade estratégica particular, que é ela mesma um produto de "estratégias e lutas políticas passadas" (BASHKAR, 1979, p. 261) e, portanto, um reflexo de um equilíbrio social de poder (passado), podemos posteriormente analisar como determinados funcionários do Estado, neste caso os formuladores de política externa, são em suas práticas moldados pelas estratégias de determinadas forças sociais que procuram transformar ou reproduzir as políticas de Estado. Embora as forças sociais sejam um termo mais amplo que apenas as forças de classe, sustentamos, como indicado, que nas sociedades capitalistas precisamos analisar, em particular, estratégias da classe capitalista que procuram reproduzir a hegemonia da classe capitalista. Quer vejamos isso em termos de elaboração de "projetos hegemônicos” (JESSOP, 1990) ou de um "conceito abrangente de controle" (OvERBEek, 2004), isto é, programas políticos que buscam servir os interesses de longo prazo de uma fração de classe hegemônica, ou conceituemos isso de outra maneira, o ponto é que sempre precisamos ver como estratégias de classe por fim são efetivadas, ou não, em termos de políticas estatais.

Novamente, enquanto as dependências estruturais podem ser parte da explicação de por que agentes do Estado buscam atender as necessidades dos proprietários do capital, evidências empíricas em uma variedade de contextos mostram que os capitalistas, na verdade, também procuram garantir que suas preferências sejam realmente conhecidas, ao invés de confiar apenas no seu "poder estrutural". Assim, um aspecto relevante da posição social que aqui distinguimos é como os formuladores de política externa - dada uma determinada seletividade estratégica do Estado, e dado o particular equilíbrio das forças de classe - estão relacionados aos interesses da classe capitalista dominante e como e em que medida suas práticas podem assim refletir determinadas estratégias da classe capitalista. Claro que devemos estar abertos à possibilidade de que as políticas estatais não se tornem congruentes com interesses da classe dominante; neste caso, é essa divergência que devemos explicar.

Portanto, devemos analisar até que ponto e de quais maneiras os agentes de Estado responsáveis pela estratégia geopolítica podem estar inseridos em determinadas redes sociais através das quais a classe capitalista exerce seu poder nas sociedades civil e política. Um canal através do qual isso pode acontecer é o dos laços pessoais diretos entre os agentes estatais e a elite da classe capitalista. Por exemplo, podemos examinar em que medida aqueles são recrutados a partir desta. Isso certamente seria um aspecto fundamental da posição social de agentes estatais 
relevantes e tenderia a moldar suas visões de mundo e perspectivas de maneira significativa. Isso também nos leva à espinhosa questão do pertencimento de classe dos próprios agentes do Estado. Uma posição aqui é que, uma vez que vivem do excedente do trabalho assalariado e estão no controle do Estado, cuja função é defender os interesses da burguesia, os agentes estatais seriam, por definição, parte da classe capitalista (DAvidSON, 2004, p. 84). Achamos que esta visão é pouco útil, pois, implicitamente, transforma todos aqueles que não são trabalhadores assalariados em capitalistas e não nos permite fazer mais distinções que, em nossa opinião, são analítica e politicamente necessárias - na verdade é tão inútil quanto considerá-los, por definição, pertencentes a uma classe social separada ou um grupo social autônomo. Essas questões devem ser resolvidas de forma empírica. Assim, os agentes de Estado podem ou não ter origem de classe capitalista, mas na medida em que o tem, o significado disso não deve ser dispensado, mesmo que este não seja o único mecanismo, nem mesmo o mais importante, por meio do qual a dominação da classe capitalista é efetuada. No entanto, a pesquisa empírica mostra que isso é importante no caso de determinados Estados capitalistas particulares, notavelmente nos EUA. Desse modo, Van Apeldoorn e De Graaff argumentam que ao longo da história de suas relações exteriores, a política externa ou os grandes estrategistas dos Estados Unidos estão intimamente ligados ou podem ser considerados os próprios membros da elite corporativa da América, o que ajuda a explicar o fato dos EUA ter consistentemente perseguido uma estratégia geopolítica que atende os interesses da fração transnacional do capital americano, que domina essas redes de elite corporativas.

A segunda dimensão estrutural à qual podemos ligar a agência dos estrategistas geopolíticos é o contexto estrutural mais amplo em que operam como tomadores de decisão e para o qual as suas estratégias estão orientadas. Funcionários do Estado envolvidos na elaboração de uma estratégia global geopolítica ou de uma grande estratégia estão obviamente voltados para um dado contexto global e internacional, ou seja, o ambiente que os funcionários do Estado, através de sua grande estratégia, procuram moldar em busca de um percebido interesse "nacional". O contexto global aqui não pode ser entendido em termos neorrealistas como pressões sistêmicas sobre os Estados, atendendo à suposta necessidade de sobreviver na anarquia. Como indicado, nenhuma raison d'etat por parte dos agentes estatais pode ser presumida. Em vez disso, como argumentamos, precisamos explicar a estratégia geopolítica, analisando suas fontes sociais. No entanto, o contexto global atua como um conjunto de estruturas que fornece restrições e oportunidades para uma estratégia geopolítica construída. 
O sistema estatal e as relações de poder dentro dele, bem como a economia mundial capitalista e suas relações sociais, constituem uma economia política global em que unidades políticas independentes e territorialmente definidas, ou seja, Estados, ocupam certa posição. Claramente, realistas, assim como os teóricos do sistema-mundo, acertam no ponto em que alguns Estados são mais poderosos do que outros. Mas o poder econômico, financeiro, político e militar de um Estado não pode, naturalmente, ser simplesmente tomado como atributo de um Estado abstraído da sociedade (o que a teoria do sistema-mundo reconhece muito melhor do que o Realismo), mas também deve estar relacionado ao poder dos capitais que residem nele e a posição que ocupam no mercado mundial e nas cadeias de valor globais. O modo como isso é então cristalizado no poder de um Estado vis-à-vis outros Estados é uma condição estrutural importante que molda a elaboração de estratégia geopolítica, na medida em que determina até que ponto um Estado (e sua classe dominante) pode moldar com êxito o ambiente em vez de apenas ser moldado por ele (mesmo que, assim, reproduzindo-o); se é capaz de estabelecer as regras para outros ou apenas tem que segui-las.

Em suma, embora a balança de poder em si não possa explicar por que determinadas estratégias são preferidas em detrimento de outras ou explicar a qual propósito social elas servem, ela define o leque de opções que os Estados possuem. Mesmo que os formuladores de política externa nem sempre reconheçam suficientemente as restrições sob as quais operam, e certamente não consigam prever todas as possíveis consequências das suas ações, os limites impostos pelo ambiente externo provavelmente afetarão a formulação de estratégia geopolítica, porque - no mínimo - contradições manifestas e limites de uma estratégia anterior (por exemplo, de governo anterior) podem levar a tentativas de ajustar a estratégia (mesmo que haja fortes razões estruturais para continuar repetindo os mesmos erros).

Precisamos salientar, retornando à nossa discussão anterior, que, com tal estrutura [F] analítica, não dissemos nada sobre a natureza particular das relações interestatais no capitalismo global. A abordagem adotada aqui não nos diz a priori se este sistema de relações internacionais capitalistas pode ser caracterizado, por exemplo, por rivalidade interimperialista, ou em vez disso, por uma cooperação e uma integração internacionais profundas ou, por exemplo, um superimperialismo americano. Essas são, de fato, questões importantes, mas pertencem a um âmbito diferente, nomeadamente, o da investigação histórica. O capitalismo global, como Teschke e Lacher (2005) também argumentam, pode, de fato, coexistir com todas essas e talvez até mais formas de relações interestatais. Essas formas histó- 
rica e geograficamente variadas devem ser vistas como resultados de processos parcialmente contingentes de práticas estatais e seus efeitos interativos, práticas intrinsecamente relacionadas à evolução das relações sociais do capitalismo global e mediadas por estratégias de classe nacionais e transnacionais. A análise materialista-histórica da política externa não deve ser carregada de ideias preconcebidas a este respeito, mas deve se concentrar em explicar a própria formulação de estratégias geopolíticas. Como elas e sua interação, na verdade, podem ser vistas como instâncias da agência através das quais o sistema internacional é reproduzido e/ou transformado, este será um passo indispensável para entender as próprias mudanças nas relações geopolíticas.

\section{CONCLUSÃO: DA SEGURANÇA NACIONAL À SEGURANÇA DA CLASSE DOMINANTE}

Neste artigo tentamos desenvolver algumas diretrizes conceituais e pontos de partida metodológicos para analisar essas estratégias de política externa a partir de uma perspectiva materialista-histórica. Embora obviamente não tenhamos sido capazes de discutir todos os aspectos teóricos relevantes de tal empenho e embora alguns aspectos que abordamos - como a natureza do Estado capitalista, a posição dos agentes estatais vis-à-vis a sociedade capitalista ou a forma como o ambiente externo (global) condiciona suas práticas - precisem ainda de teorização mais meticulosa do que pudemos fornecer dentro do escopo deste artigo, nós também devemos ter em mente que nenhuma quantidade de teorização pode substituir pesquisas empíricas necessárias. Dada a escassez de análises materialista-históricas de política externa, muito trabalho ainda está por vir.

Adotando a perspectiva delineada aqui, uma pesquisa nos permitiria descobrir as fontes sociais escondidas da estratégia geopolítica conduzida por Estados capitalistas. Enquanto, por exemplo, o Neorrealismo vê a política externa em termos de uma estratégia racional de maximização da "segurança nacional", a abordagem materialista-histórica defendida acima permitiria desconstruir o conceito realista de "segurança nacional" e examinar em que medida podemos reconstruí-lo como "segurança da classe dominante", isto é, essas estratégias, na verdade, refletem (não sempre perfeitamente) estratégias da classe capitalista que procuram reproduzir a hegemonia de classe. Não estamos dizendo que este é sempre o caso, ou deve ser o caso, dada certa lógica funcionalista - as estratégias de classe podem falhar! No entanto, enquanto a classe capitalista de fato continuar a ser a classe dominante, então sua dominação deve também, na maioria das vezes, ser expressa em estratégia(s) geopolítica(s) de Estado com pelo menos um mínimo de sucesso. Portanto, a chamada segurança nacional é muitas vezes, de fato, a segurança da 
classe dominante e, por conseguinte, a segurança de uma determinada ordem socioeconômica. Notemos, então, que isso não significa apenas a obviedade que, ao falarmos das classes dominantes nacionais, estamos falando da sua sobrevivência física ligada à sobrevivência de seu respectivo Estado. Neste caso, a segurança nacional em sentido realista e a segurança da classe capitalista simplesmente coincidiriam e a lógica (neo)realista e sua explicação do comportamento da política externa poderiam ser suficientes (com o Estado e a "sua" classe dominante enfrentando o mesmo dilema da segurança). Pode haver situações em que este seja o caso, ou seja, quando um Estado enfrenta uma ameaça externa real contra a qual se defende, então a defesa do Estado é ipso facto também a defesa de sua classe dominante ${ }^{17}$. Na maioria das vezes, no entanto, como visto no Neorrealismo, a sobrevivência real de um Estado não está em jogo. Podemos até questionar até que ponto esta luta pela sobrevivência é (ainda) a característica fundamental da política internacional. Portanto, o que queremos dizer, em vez disso, é que a estratégia geopolítica serve a um determinado propósito social: está vinculada aos interesses de uma (fração de) classe dominante e à manutenção de seu sistema de dominação doméstico (e onde for aplicável, internacional e transnacionalmente). Se este propósito não servir efetivamente a ela em longo prazo, o sistema pode entrar em colapso. Em outras palavras, se a estratégia certa não for "implementada", o que pode acontecer não é que um Estado perca sua independência (formal) ou mesmo tenha a sua segurança minada; não, o que pode acontecer é que os grupos ou classes sociais que são atualmente superiores perdem (parte do) seu poder ou pelo menos são forçados a fazer compromissos com classes subordinadas que, de outra forma, não estão dispostos a fazer. Assim, os casos do imperialismo britânico e estadunidense mostram que o imperialismo como solução para o problema recorrente da superacumulação foi preferido, pela perspectiva das elites dominantes, em comparação com soluções alternativas "domésticas" e mais progressivas, como a redistribuição e outras reformas socioeconômicas que permitissem absorver o excedente de capital $^{18}$. Como estas implicariam necessariamente compromissos e concessões de classe que limitariam o poder e os privilégios das classes dominantes britânicas e estadunidenses, tal solução era politicamente inviável.

O que aqui claramente vem à tona é como uma abordagem materialista-histórica em análise da política externa nos permite recuperar plenamente a natureza política da política externa; e não (meramente) a política de Estado contra Estado,

17 Supondo que o Estado conquistador não deixaria sua dominação intacta (BrEnNER, 2006, p. 82). 18 Ver Harvey (2003), p. 126. Quanto ao caso dos Estados Unidos ver Van Apeldoorn e De Graaff (2012b) e Van Apeldoorn e De Graaff (2014). 
abstraída de suas sociedades, mas a política de atores humanos reais (coletivos), de grupos e classes, seus interesses e aspirações.

\section{REFERÊNCIAS BIBLIOGRÁFICAS}

Aluison, Graham Tillett. Essence of Decision: Explaining the Cuban Missile Crisis. Boston: Little, Brown, 1971.

Allison, Jamie; Anievas, Alexander. "Approaching the international Beyond Political Marxism”. In: Anievas, Alexander (org.). Marxism and World Politics: Contesting Capitalism. London, New York: Routledge, 2010, p. 197-214.

Anderson, Perry. Lineages of the Absolutist State. London: New Left Books, 1974.

Anievas, Alexander. Theories of Global States: A Critique. Historical Materialism, No.16, p. 190-206, 2008.

Marxism and World Politics: Contesting Capitalism. London, New York:

Routledge, 2010.

The international political economy of appeasement: the social sources of

British foreign policy during the 1930s. In: Review of International Studies, Vol. 37, No. 2, p. 601-629, 2011.

Archer, Margaret. Realist Social Theory: The Morphogenetic Approach. Cambridge: Cambridge University Press, 1995.

Arrighi, Giovanni. The Long Twentieth Century. London: Verso, 1994.

BHASKar, Roy. The Possibility of Naturalism: A Philosophical Critique of the Contemporary Human Sciences. Brighton: Harvester Press, 1979.

BLock, Fred. Revising State Theory: Essays in Politics and Postindustrialism. Philadelphia: Temple University Press, 1987.

BRENNER, Robert. What Is, and What Is Not, Imperialism? Historical Materialism, vol. 14, No. 4, p. 80-81, 2006.

Breuning, Marijke. Foreign Policy Analysis: A Comparative Introduction. Basingstoke,

New York: Palgrave MacMillan, 2007.

CAFruny, Alan; RaYner, Magnus. Europe at Bay: In the Shadow of U.S. Hegemony. Boulder, Colorado: Lynne Rienner Publishers, 2007.

Carlsnaes, Walter; Guzzini, Stefano. Foreign Policy Analysis, 5 vols. London: Sage, 2011. Callinicos, Alex. Does capitalism need the state system? Cambridge Review of International Affairs, Vol. 20, No. 4, p. 533-549, 2007.

Callinicos, Alex. Imperialism and Global Political Economy. Cambridge and Malden, MA. Polity Press, 2009. 
Callinicos, Alex; Rosenberg, Justin. Uneven and combined development: the socialrelational substratum of the international? An exchange of letters. Cambridge Review of International Relations, Vol. 1, No. 1, p. 77-112, $2007 \mathrm{~b}$.

CARroll, William K. The Making of a Transnational Capitalist Class: corporate Power in the 21st Century. London: Zed Books, 2010.

DAvidson, Neil. “Many capitals, many states: Contingency, logic or mediation?”. In: AnIEvas, Alexander (org.). Marxism and World Politics: Contesting Capitalism. London, New York: Routledge, 2010, p. 77-93.

Graham, T. Allison. Essence of Decision: Explaining the Cuban Missile Crisis. Boston: Little, Brown, 1971.

HALPERIN, Sandra. Anglo-American Political Economy and Global Restructuring: The Case of Iraq. Spectrum: Journal of Global Studies, Vol. 1, No.1, p. 12- 32, 2009.

Harvey, David. The New Imperialism. Oxford, New York: Oxford University Press, 2003. Hudson, Valerie. Foreign Policy Analysis: Actor-Specific Theory and the Ground of International Relations. Foreign Policy Analysis, Vol.1, No.1, p. 1-30, 2005. Foreign Policy Analysis: Classic and Contemporary Theory. Lanham, MD: Rowman and Littlefield, 2007.

Jessop, Bob. State Theory: Putting the Capitalist State in its Place. Cambridge: Polity, 1990. "Dialogue of the Deaf: Some Reflections on the Poulantzas- Miliband Debate". In: Wetherly, Paul; Barrow, Clyde; Burnham, Peter. Class, Power and the State in Capitalist Society: Essays on Ralph Miliband. Basingstoke, New York: Palgrave Macmillan, 2008, p. 132-57.

LACHER, Hannes. International transformation and the persistence of territoriality: toward a new political geography of capitalism, Review of International Political Economy Vol. 12, No. 1, p. 26-52, 2005.

LaYne, Christopher. The Peace of Illusions: American Grand Strategy from 1940 s to the Present. Ithaca, London: Cornell University Press, 2006.

Mearsheimer, John. The Tragedy of Great Powers. New York, London: W. W. Norton \& Company, 2001.

Overbeer, Henk. Transnational class formation and concepts of control: notes towards a genealogy of the Amsterdam Project in International Political Economy. Journal of International Relations and Development, Vol. 7, No. 2, p. 113-41, 2004.

Pozo-Martin, Gonzalo. Autonomous or materialist geopolitics?. Cambridge Review of International Affairs, Vol. 20, No. 4, p. 551- 63, 2007.

Robinson, William. A Theory of Global Capitalism: Transnational Production, Transnational Capitalists and the Transnational State. Baltimore: Johns Hopkins University Press, 2004. 
. Beyond the Theory of Imperialism: Global Capitalism and the Transnational

State. Societies Without Borders, Vol. 5, No.2, p. 5-26, 2007.

The Pitfalls of Realist Analysis of Global Capitalism: A Critique of Ellen

Meiskins Wood's Empire of Capital. Historical Materialism, No. 15, p. 71-93, $2007 \mathrm{~b}$.

Rosenberg, Justin. The Empire of Civil Society: A Critique of the Realist Theory of

International Relations. London, New York: Verso, 1994.

RuPERT, Mark. "Alienation, Capitalism, and the Inter-State System: Towards a Marxian /

Gramscian Critique”. In: Gill, Stephen (org.). Gramsci, Historical Materialism and

International Relations. Cambridge: Cambridge University Press, 1993, p. 67-92.

RuPERT, Mark; Smith, Hazel. Historical Materialism and Globalization. New York: Routledge, 2002.

Smith, Steve; Hadfield, Amalia; Dunne, Tim. "Introduction”. In: Smith, Steve; Hadfield, Amalia; Dunne, Tim (orgs.). Foreign Policy: Theories, Actors, Cases. Oxford: Oxford University Press, 2008, p. 1-8.

Teschke, Benno. The Myth of 1648: Class, Geopolitics and the Making of Modern International Relations. London: Verso, 2003.

Teschke, Benno; Lacher, Hannes. The changing "Logics" of Capitalist Competition. Cambridge Review of International Affairs, Vol. 20, No. 4, p. 565-80, 2007.

Van Apeldoorn, Bastiaan; De Graaff, Naná. The Limits of the Open Door and the US State-Capital Nexus. Globalizations, Vol. 9, No.4, p. 539-608, 2012.

. Corporate Elite Networks and Us Post-Cold War Grand Strategy from Clinton

to Obama. European Journal of International Relations, Vol. 20, No. 1, p.29-55, June, 2012b.

. American Grand Strategy and Corporate Elite Networks: The Open Door

and its Variations since the End of the Cold War. London, New York: Routledge, 2014. Van Der Pijl, Kees. The Making of an Atlantic Ruling Class. London: Verso, 1984.

Transnational Classes and International Relations. London, New York: Verso, 1998.

Global Rivalries: From Cold War to Iraq. London, Ann Arbor, MI: Pluto Press, 2006.

Nomads and Empires. London, New York: Verso, 2007.

Capital and the state system: a class act. Cambridge Review of International Affairs, Vol. 20, No. 4, p. 619-637, 2007.

Wallerstein, Immanuel. The Modern World-System, part I. New York: Academic Press, 1974 .

WALtz, Kenneth Neal. Theory of International Politics. New York: McGraw-Hills, 1979. 
Wight, Colin. State agency and human activity. Review of International Studies, Vol. 30, No. 2, 2004. p. 269-280.

WooD, Ellen Meiksins. Democracy against Capitalism. Cambridge: Cambridge University Press, 1995.

Ellen Meiksins. Empire of Capital. London, New York: Verso, 2003.

Ellen Meiksins. "Democracy as Ideology of Empire”. In: Mooers, Colin (org.). The New Imperialists: Ideologies of Empire. Oxford: Oneworld Publications, 2006. p. 9-23. 